\title{
SIMULATION ANALYSIS OF SHELL AND TUBE HEAT EXCHANGER USING DIFFERENT FLUIDS
}

\author{
Rajesh Papatla ${ }^{\# 1}$ Anil Kumar Ch ${ }^{\# 2}$ K.Supriya ${ }^{\# 3}$ Ch.S.R.T.P.Sai ${ }^{\# 4}$ \\ \#2, 3,4 Department of Mechanical Engineering DVR \& Dr HS MIC college of Technology \\ Kanchikacherla, Andhra Pradesh, India.
}

\section{ABSTRACT}

There are many models to characterize the behavior of the heat exchangers encountered in many industries. There are several correlations available, so that the heat transferred and the thermal stresses can be evaluated. Shell and Tube heat exchangers are having special importance in boilers, oil coolers, condensers, and pre -heaters. They are also widely used in process applications as well as the refrigeration and air conditioning industry. The robustness and medium weighted shape of Shell and Tube heat exchangers make them well suited for high-pressure operations. he present work deals with the design and analysis of water-cooled shell and tube condenser and we have shown how to done the thermal analysis by using theoretical formula, for this we have chosen an industrial problem of 8 ton capacity of counter flow shell and tube heat exchanger of water type. The condenser is designed using theoretical procedures. The condenser is modeled by using the dimensions obtained from the design procedures. Then thermal analysis is carried out in Solid workflow simulation. The results obtained through the analysis are discussed in detail and compared with analytic values.

Keywords: Condenser, Shell and Tube Heat Exchanger, Thermal Analysis and Solid Work Flow Simulation

\section{Corresponding author: Rajesh Papatla.}

\section{INTRODUCTION}

Water-cooled shell \& tube condenser is an important component of the refrigeration and air-conditioning systems. The condenser removes the heat from refrigerant carried from evaporator and added by compressor and convert the vapor into liquid refrigerant. It is a heat exchanger in which heat transfer takes place from high temperature vapor refrigerant to low temperature water, which is used as cooling medium. These condensers are always preferred where adequate supply of clean and inexpensive means of water disposal is available. Shell \& tube condensers are those in which heat transfer occurs between two fluid streams, which do not mix or physically contact each other. The fluids so involved are separated from one another by a tube as well as wall, which may be involved in the heat transfer path. Heat transfer will thus occur by convection from the hot fluid surface, by conduction through the solid and again by convection from the solid surface to the cooler fluid.

Many types of condensers have been developed to meet the widely varying applications. "Shell \& Tube" arrangements are often used, where heat transfer effectiveness and reliability are important. The present industrial services require water- cooled shell \& tube condenser, as the quantity of heat to be transferred is large. These condensers occupy considerable ground area. A combination of space, cost and pressure drop limitations usually results in a preference for the more compact "shell \& tube condensers". These condensers consist of a bundle of tubes through which one fluid passes and this is enclosed by the shell, which contains the other fluid. If one of the fluids is to be condensed or vaporized, it is 
generally introduced to shell side. The tube side fluid may make numerous passes of the bundle, but shell fluid flows through the shell only once and therefore it is said to have one shell pass. The condensers may have more than one shell pass depending upon the requirements. The shell side fluid may be forced to follow a devious path over the outside surface of the tubes by cross and longitudinal baffles inserted among the tubes. Shell \& tube condensers can be connected in series or parallel either or both the streams. Shell and tube condenser is universally used for all high capacity units and it is most satisfactory among all the types of condensers. These condensers are available from 2 to 1000 tons' capacity units. The condenser should be designed to dissipate the sum of the heat absorbed by the evaporator and the work of compression and to provide adequate sub cooling to the liquid refrigerant in order to improve the cycle efficiency. Design of shell and tube condensers usually involves compromise of various aspects among the several design factors like Temperatures, Pressure Levels, Corrosion, Toxicity and Scale forming tendency. The weight, size and cost considerations are also important. In spite of the extensive investigations in this field, design of condenser is still as an art rather than a science.

\section{DETAILS OF PRIMARY REFRIGERATION SYSTEM}

\section{Condenser}

Liquid Line Filter/Drier

Sub-cooler

Liquid Line Sight Glass

Expansion Valve

Evaporator

Super heater

HP/LP cutout
: Water-Cooled, shell-in-Tube.

: Provided

: Encased in the pot-2.

: Provided at two places.

: Pneumatically operated (automatic operation)

: Immersed in the secondary pot- 1 .

: Encased in pot-3.

: Provided.

The Isolation Valves are provided at the compressor suction and compressor discharge connections. Valves are also provided at various locations for maintenance purpose. Optically and at additional cost, an arrangement can also be made to install second compressor while the first compressor is being tested. Once the first compressor test is over, close the isolation valves for the first compressor to isolate it from the circuit. Now open the valves for the second compressor and start the test immediately. The first compressor can now be replaced with another compressor with another compressor, evacuated, and charged subsequently. The primary refrigeration circuit can be cleaned easily. The fare connections are provided, as far as possible.

Table: The rated conditions of AW compressors are: (According to ASHRAE)

3. SOLID WORKS FLOW SIMULATION

\begin{tabular}{|c|c|c|c|c|}
\hline \multirow{2}{*}{$\begin{array}{c}\text { OPERATING CONDITIONS } \\
\text { (R-22) }\end{array}$} & \multicolumn{2}{|c|}{ UNIITS } & \multicolumn{2}{|c|}{$\mathrm{R}-22$} \\
\hline & MKS & FPS & MKS & FPS \\
\hline Evaporating Temperature & ${ }^{\circ} \mathrm{C} \pm 0.5$ & ${ }^{\circ} \mathrm{F} \pm 1$ & 7.2 & 45 \\
\hline Condensing Temperature & ${ }^{\circ} \mathrm{C} \pm 1$ & ${ }^{\circ} \mathrm{F} \pm 1.8$ & 55 & 131 \\
\hline Liquid sub cooled temperature & ${ }^{\circ} \mathrm{C} \pm 1$ & ${ }^{\circ} \mathrm{F} \pm 1.8$ & 46 & 115 \\
\hline Return gas temperature & ${ }^{\circ} \mathrm{C} \pm 1$ & ${ }^{\circ} \mathrm{F} \pm 1.8$ & 35 & 95 \\
\hline Ambient temperature & ${ }^{\circ} \mathrm{C} \pm 1$ & ${ }^{\circ} \mathrm{F} \pm 1.8$ & 35 & 95 \\
\hline Suction pressure (Gauge) & $\mathrm{Kgf} / \mathrm{cm}^{2}$ & Lbf/in ${ }^{2}$ & 5.3 & 76 \\
\hline Discharge pressure (Gauge) & $\mathrm{Kgf} / \mathrm{cm}^{2}$ & $\mathrm{Lbf} / \mathrm{in}^{2}$ & 21 & 300 \\
\hline
\end{tabular}


Engineering Fluid Dynamics (EFD) is a new breed of Computational Fluid Dynamics (CFD) soft ware that enables mechanical engineers to simulate fluid flow and heat transfer applications with powerful, intuitive, and accessible 3D tools. Engineering fluid dynamics is driven by engineering criteria and goals so every product engineer can get the technical insights necessary to answer the questions faced in the product development process. SolidWorks ${ }^{\circledR}$ Flow Simulation is based on the same mathematical foundation as traditional computational fluid dynamics (CFD) soft ware, but key benefits set Solid Works Flow Simulation apart, making it quicker and easier to use, while still delivering a robust and highly accurate solution.

\section{Reason 1: Using Existing Geometry}

With most traditional CFD programs, you need to modify settings substantially and then transfer existing CAD models to a different program in order to create a model for analysis. The main reason is that traditional CFD programs require a considerable amount of manual intervention. The translation process might work for 80 percent of the geometry but the rest has to be re-created or simplified by hand. Some users have reported wasting days waiting for their model to be transferred - if it succeeds at all! Therefore, many users have found it more reliable to start from scratch by creating the geometry in the CFD program (although this activity also involves a considerable expenditure of time). Recently a company testing a traditional tool popular in the aerospace industry reported a difference of two weeks compared to two days with SolidWorks Flow Simulation technology. They reported that they spent a majority of their two weeks trying to get their geometry into their current traditional CFD tool. However, the same complex geometry was transferred into SolidWorks Flow Simulation and analyzed in under two days - a significant savings. The main difference is that Solid Works Flow Simulation uses native SolidWorks 3D CAD data directly for fluid flow simulation. The fluid domain is automatically created based on the geometry and then is automatically updated for any design changes.

Flow conditions are defined directly on the SolidWorks CAD model and organized similarly to other design data in the feature tree. As a result, the original SolidWorks CAD model is used natively for the analysis with SolidWorks Flow Simulation, saving preparation time and making sure the design updates are taken into account for the CFD analysis.

\section{Reason 2: Handling Complex Geometry}

To understand how your design behaves in real-world conditions, you need to simulate its performance in its operating environment. All analysis vendors recommend that you defeature your models. Then how do you know how far to take it and whether your analysis results will actually reflect their field conditions? geometries. It can easily handle CAD geometries containing tight crevices and sharp angles without needing to defeature the model. However, if you decide to simplify your model, you have access to powerful simplifi cation geometrical features for preparing your model for the CFD analysis.

\section{Reason 3: Effortless Meshing}

In a standard CFD package, obtaining an optimum mesh is not easy. However, this is perhaps one of the most important steps in the analysis process. After all, meshing directly affects the accuracy of the results. One airplane engine manufacturer spends a minimum of three months on finding the best mesh for its designs. While automatic meshes have long been available, traditional CFD tools still require a considerable amount of manual intervention in order to maintain the quality of the mesh by eliminating gaps and overlaps, and maintaining the required skewness, aspect ratio, warpage, and volume of individual cells. This manual process has to be repeated for every design change.

Solid Works Flow Simulation offers you extremely robust automatic meshes for fluid and solid regions with automatic mesh refinement/unrefinement due to geometrical or physical requirements. SolidWorks Flow Simulation also features grid-independent near-wall 
modeling by using Partial Cells technology. This technology enables the soft ware to correctly simulate the boundary layer phenomena for fluid flow and heat transfer effects. The result is that new parts and design changes can be meshed in a matter of minutes, dramatically reducing the time required for analysis.

\section{Reason 4: Creating Additional Geometry Is Unnecessary}

When conducting fluid flow or thermal analysis, you are interested in understanding what is happening in the empty region (the fluid) and how it affects the solids, which it meets. However, the space, which is filled with liquid or gas, is not normally modeled as a separate solid in the design. Other analysis programs require you to create additional geometry in your solid modeler to represent this region. While some programs can create solids for internal fl own volumes automatically, unfortunately, they do it indiscriminately. Therefore, they create solids even for unnecessary isolated volumes that you're not interested in analyzing.SolidWorks Flow Simulation automatically creates the fluid domain and can identify all "empty" spaces - the enclosed internal fl own space and the outer fl own area, as well as the solid areas of different materials involved in heat transfer. In addition, it excludes cavities without fl own conditions to avoid unnecessary mesh creation.

\section{Reason 5: Large Community of Users}

The SolidWorks Community is a large product engineers community developing innovative, best-in-class products worldwide. Thousands of SolidWorks companies in high tech, life science, and industrial equipment benefit from SolidWorks Flow Simulation to develop their product with CFD insight. Moreover, SolidWorks Flow Simulation is included in the SolidWorks educational offer so students - future engineers-learn virtual simulation and CFD with this unique engineering approach.

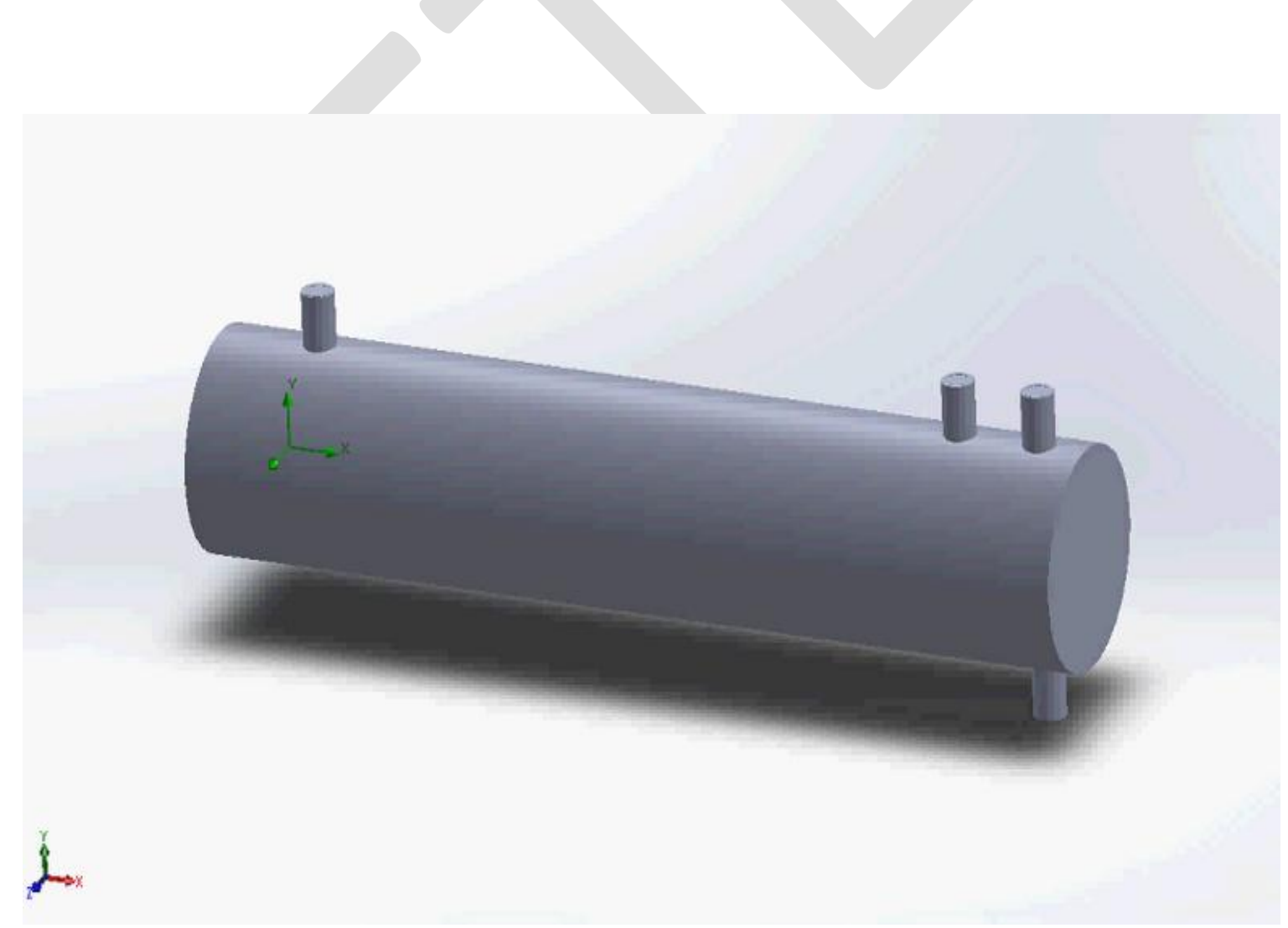

Fig: Shell and tube heat exchanger imported from UNIGRAPHICS 
DOI : https://dx.doi.org/10.26808/rs.ed.i8v1.01

International Journal of Emerging Trends in Engineering and Development

Issue 8, Vol.1 (January 2018)

Available online on http://www.rspublication.com/ijeted/ijeted_index.htm

ISSN 2249-6149

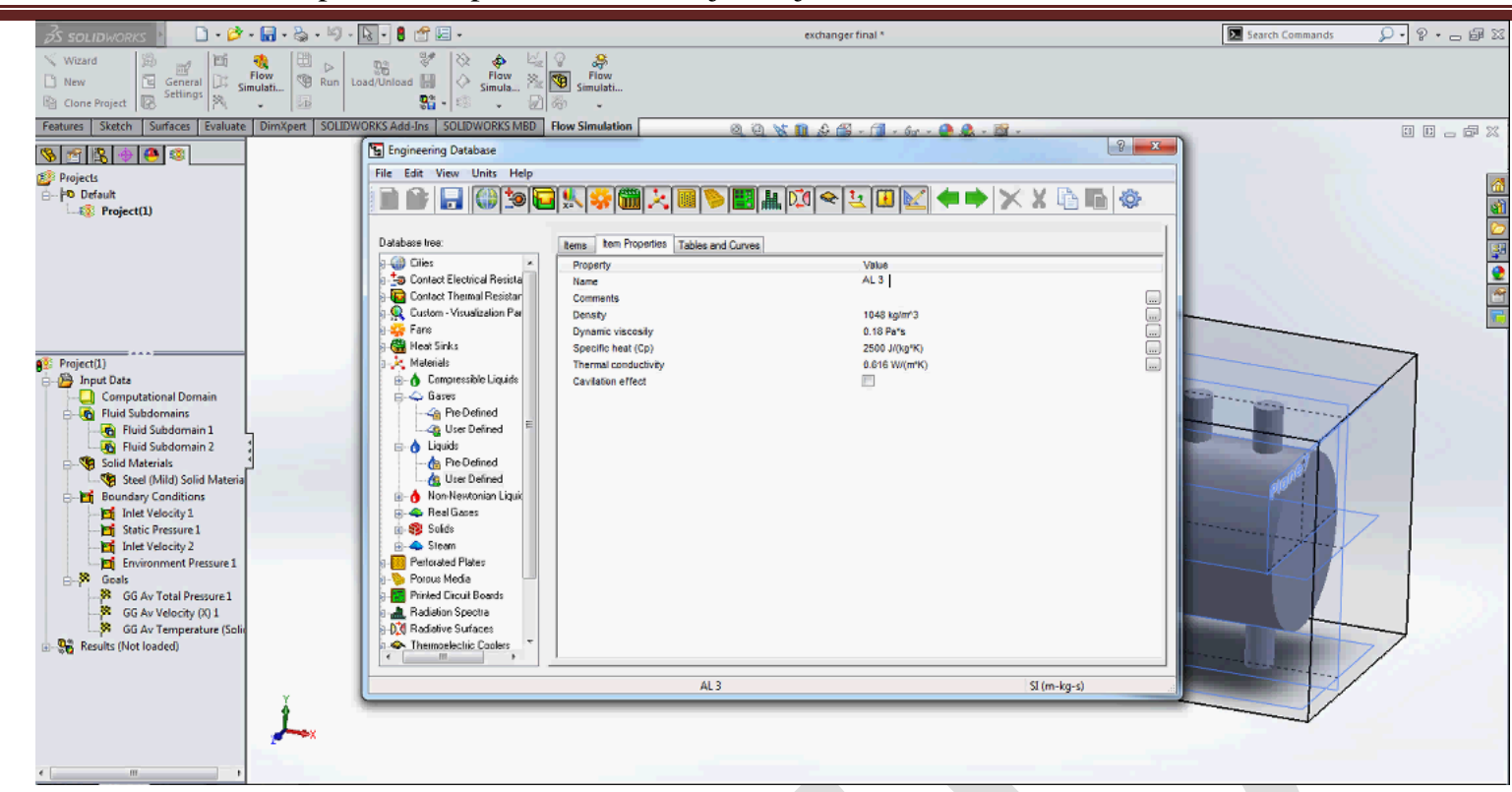

Fig: Material properties entering process in SOLIDWORKS

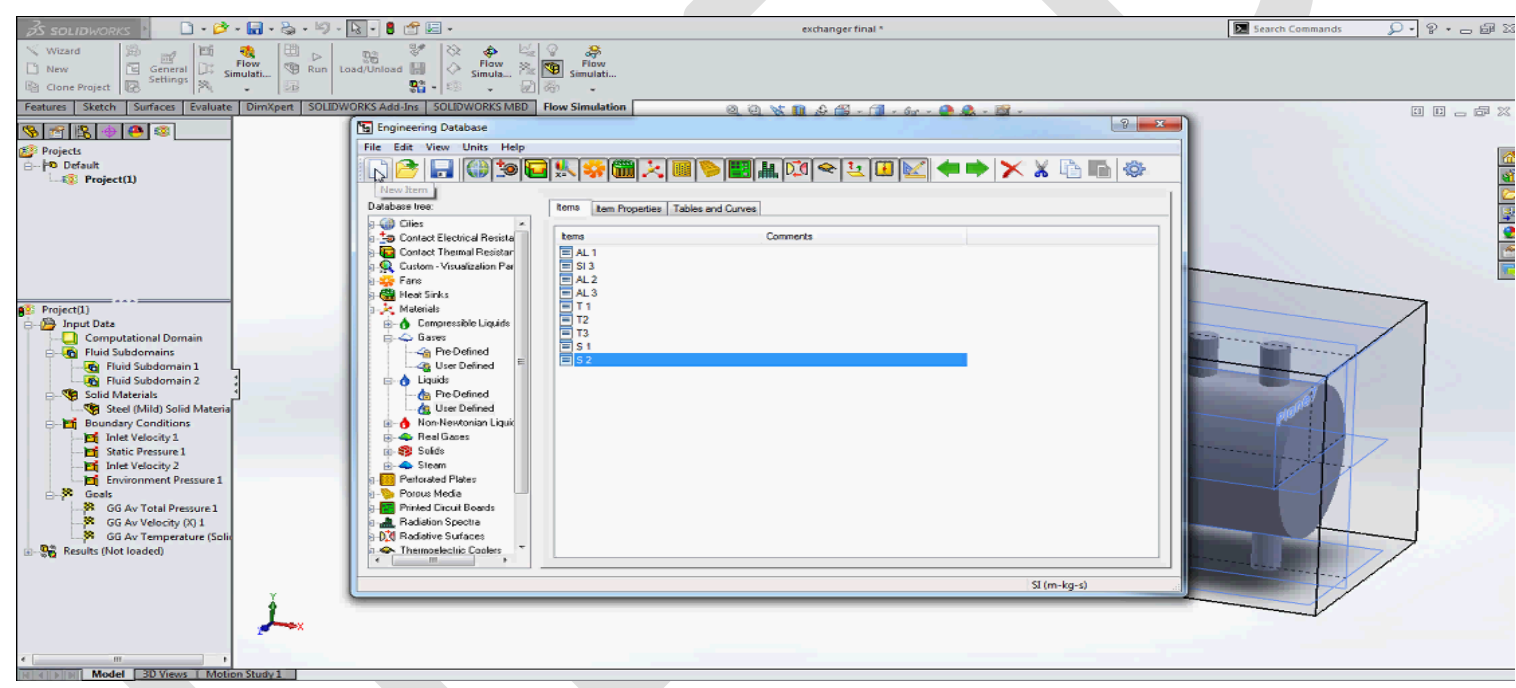

Fig: Materials considered in SOLID WORKS flow simulation software

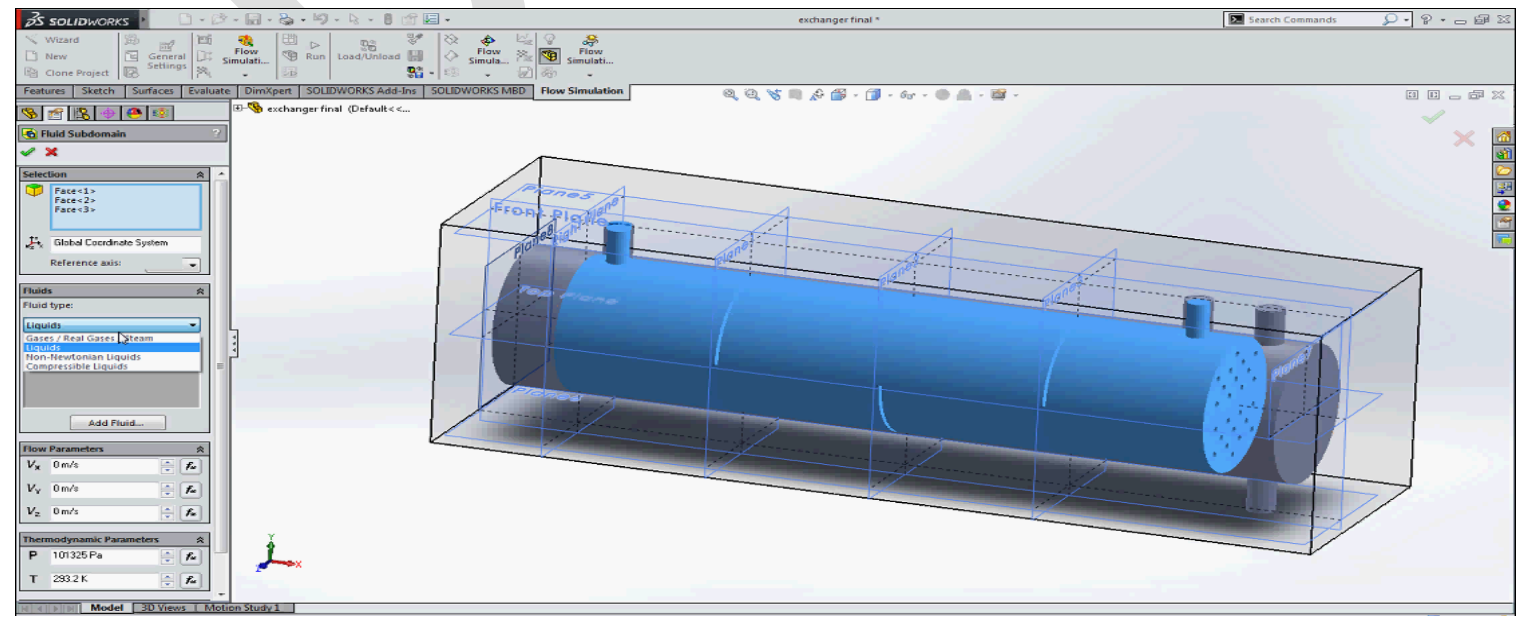

Fig: Fluid domain created in SOLIDWORKS 
DOI : https://dx.doi.org/10.26808/rs.ed.i8v1.01

International Journal of Emerging Trends in Engineering and Development

Issue 8, Vol.1 (January 2018)

Available online on http://www.rspublication.com/ijeted/ijeted_index.htm

ISSN 2249-6149

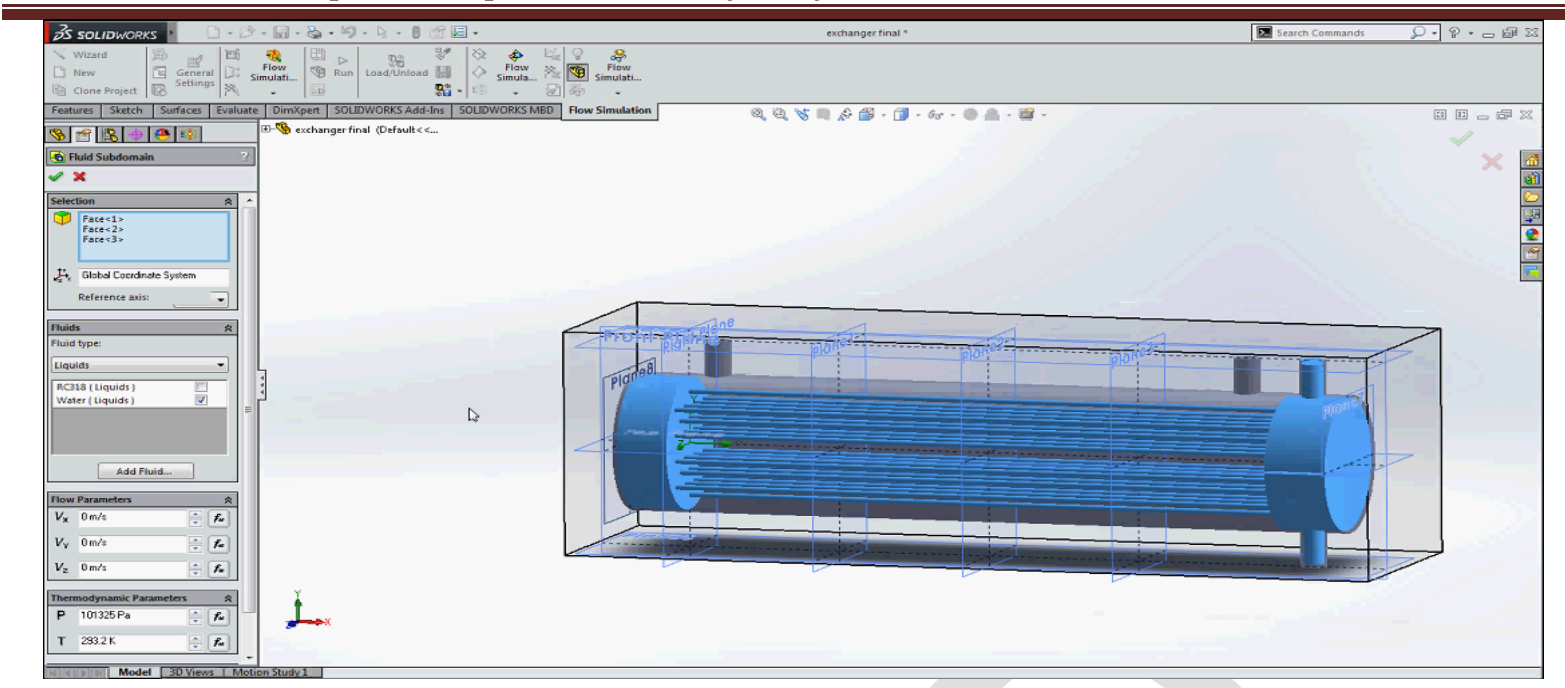

Fig: Water domain in pipes created in SOLIDWORKS

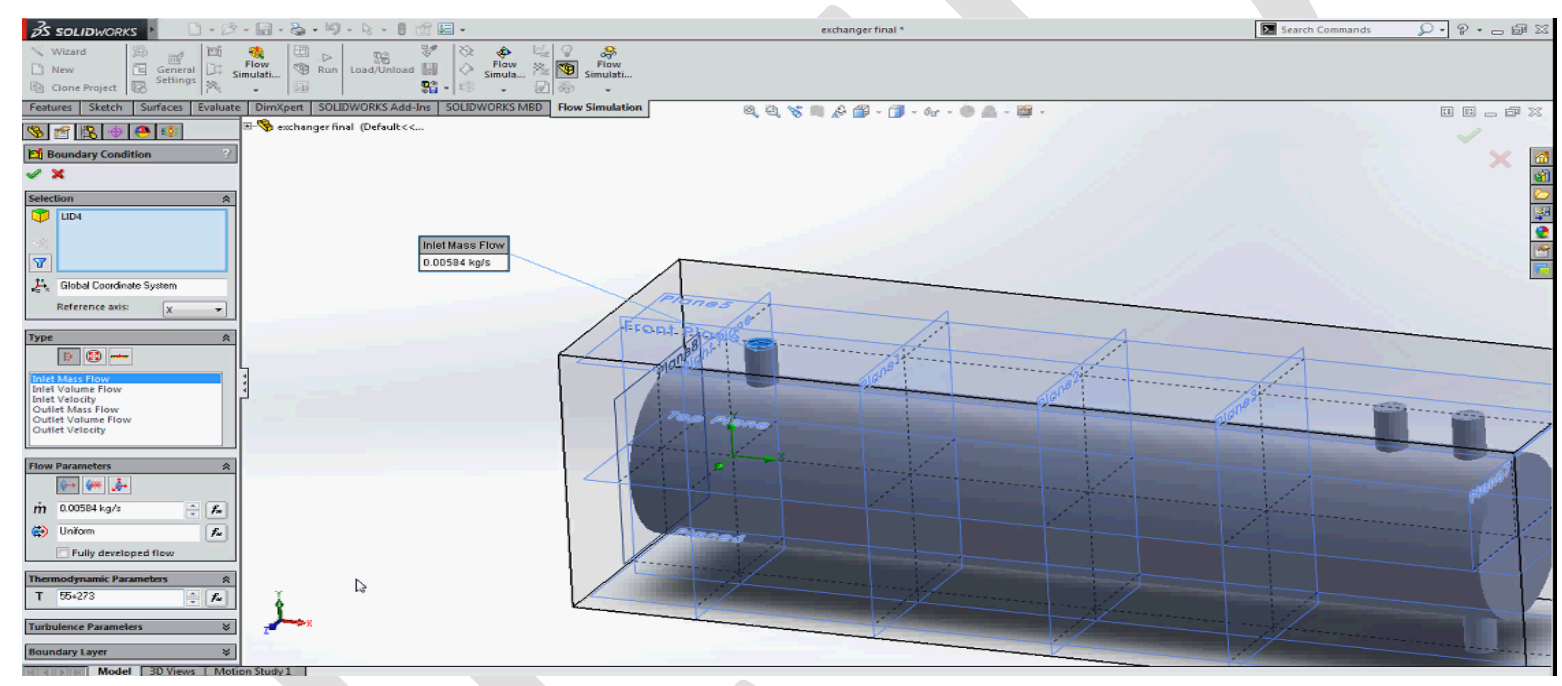

Fig: Velocity and temperature of Inlet of shell

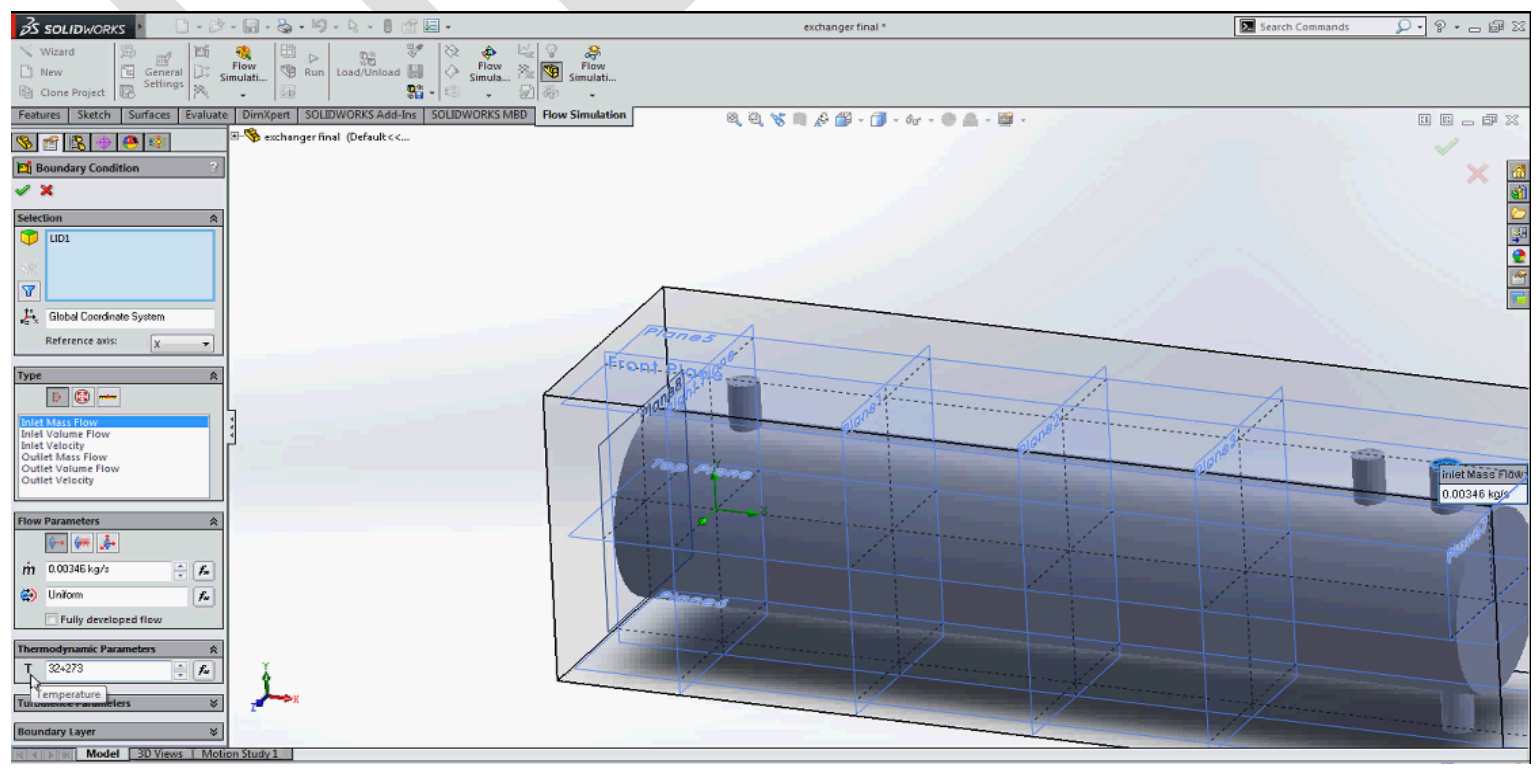

Fig: Temperature and velocity of tube inlet 


\section{RESULTS AND DISCUSSION}

The Finite Element Method (FEM) has become a powerful tool for the numerical solutions of a wide range of engineering problems. FEM is being extensively used all over the world for obtaining approximate numerical solutions for a large varieties of problems, and it has become an indispensable tool, in particular, in the field of stress analysis.

This work focuses on analyzing the temperature distribution of shell and tube condenser. The problem is solved in solid works flow simulation. To solve the problem in Ansys, basically some assumptions are made. They are as follows.

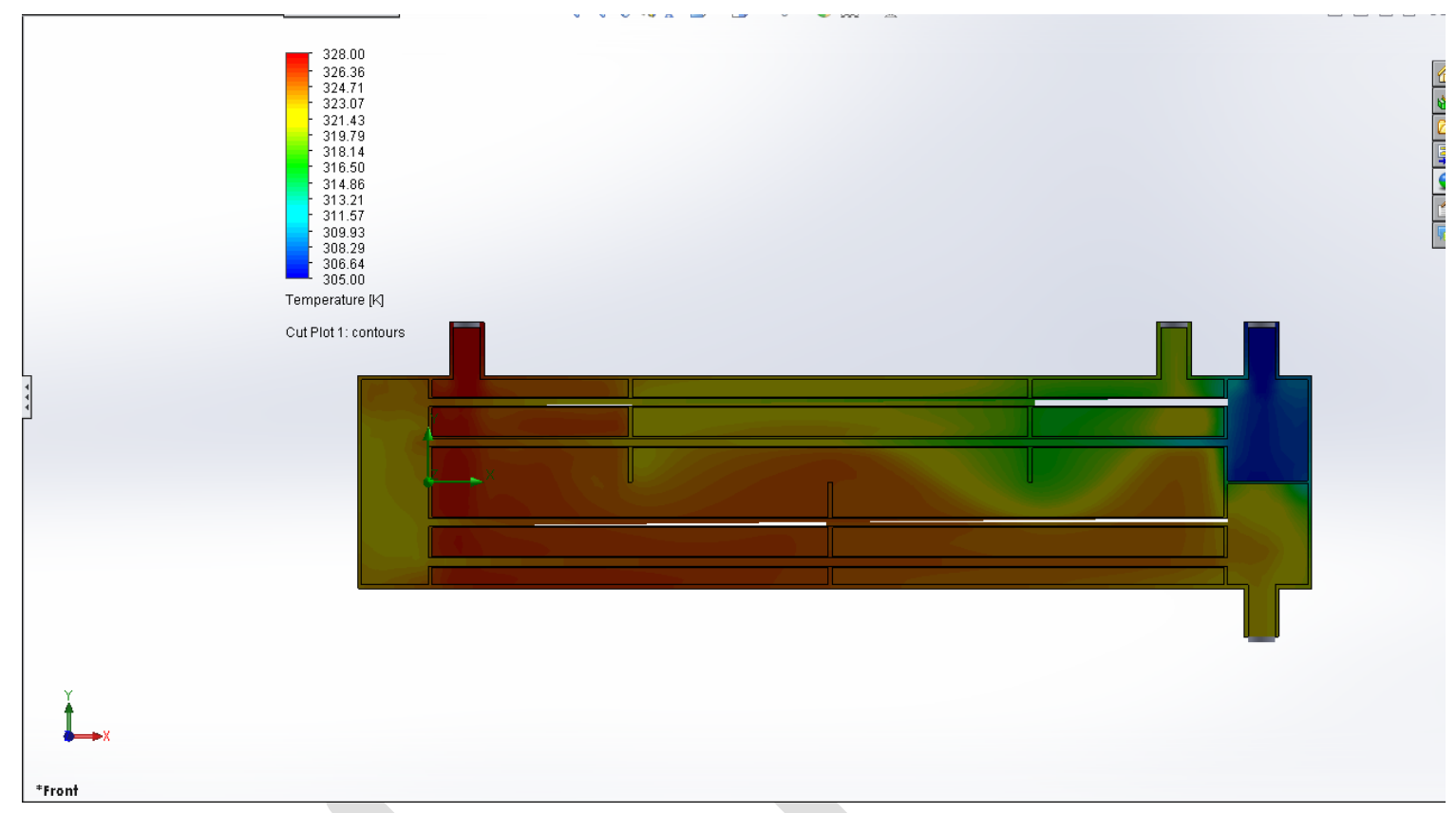

Fig: Temperature distribution of water in shell and tube

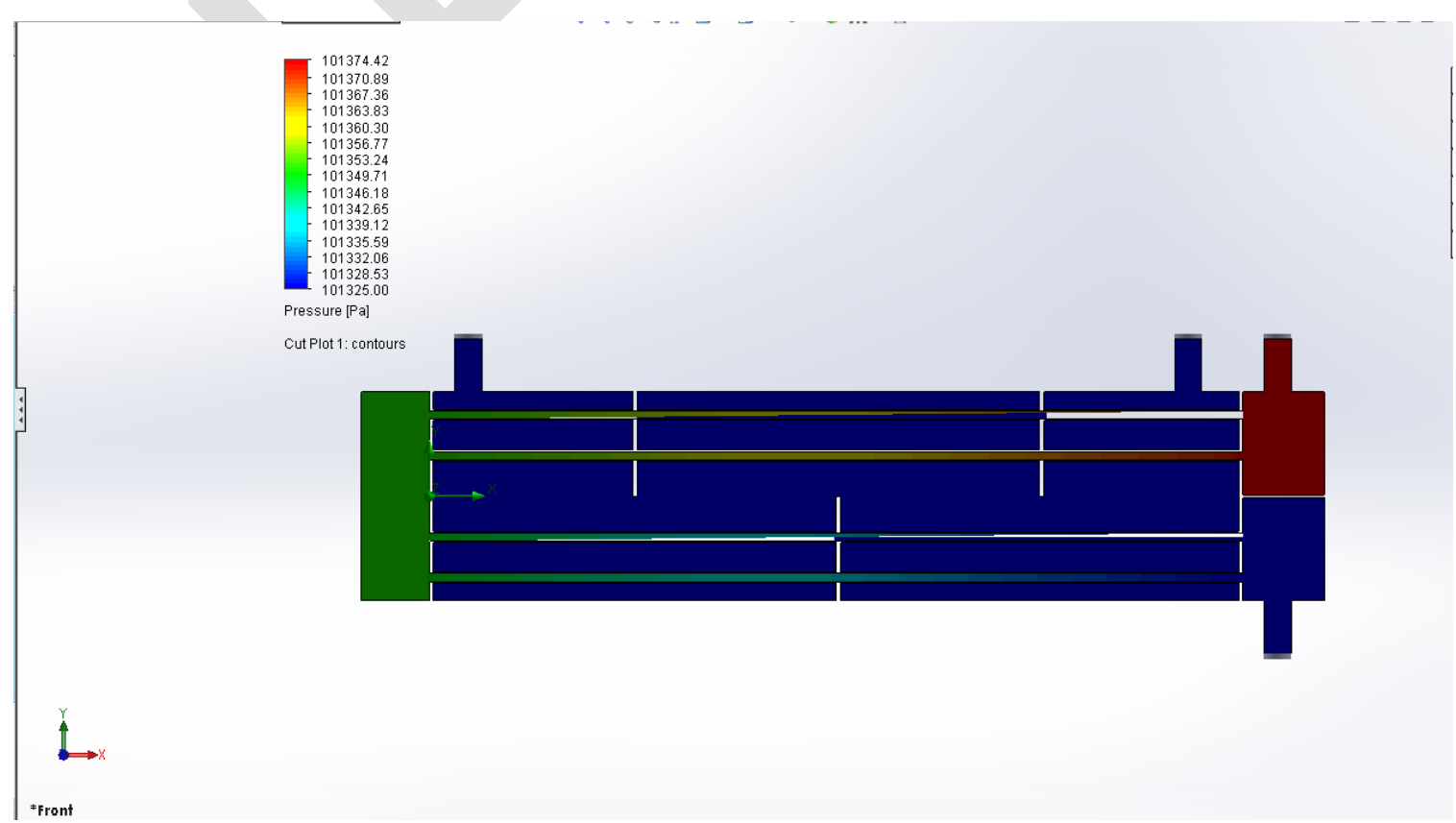

Fig: Pressure distribution in shell and tube 


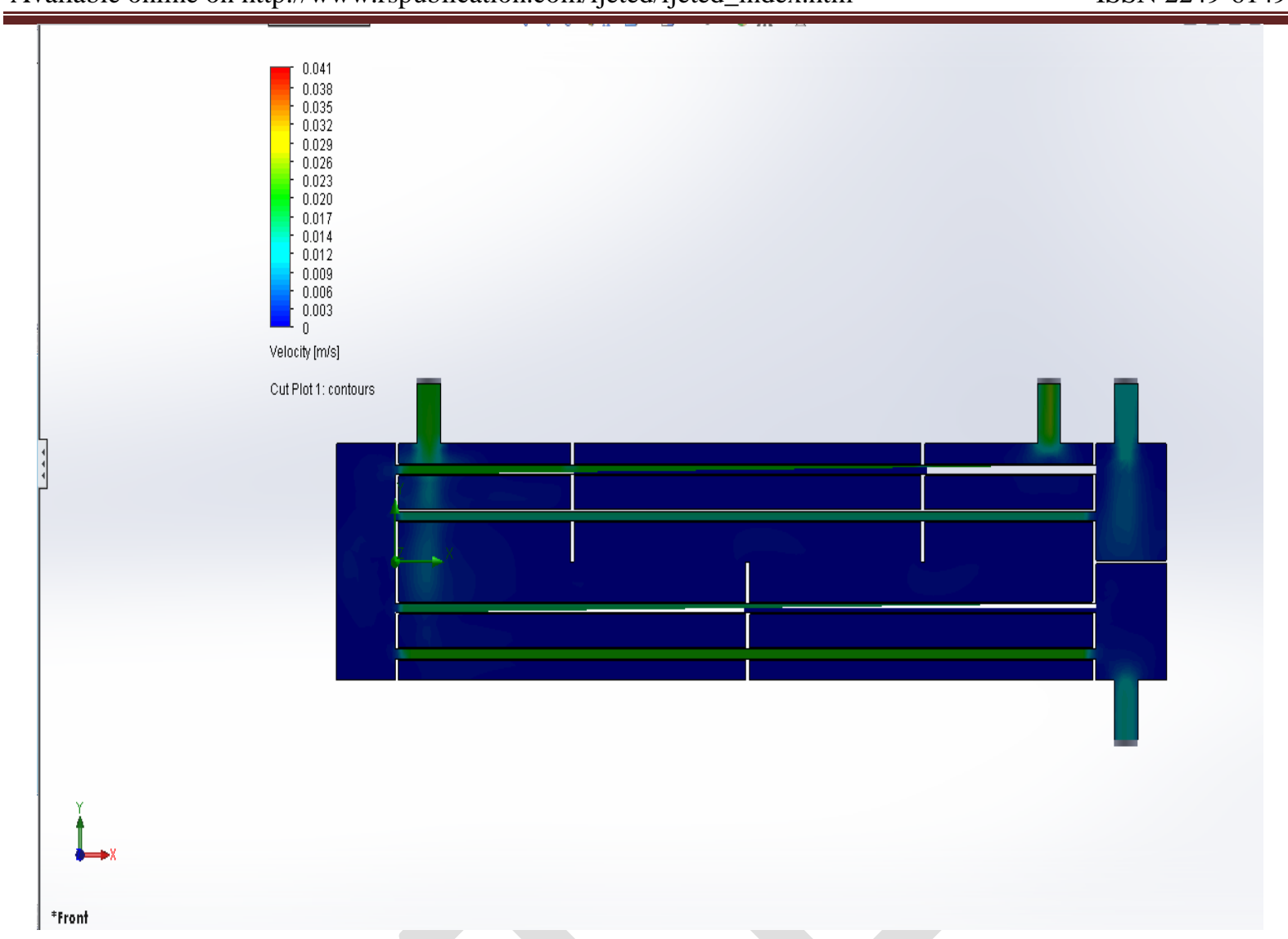

Fig: Velocity distribution of shell and tube

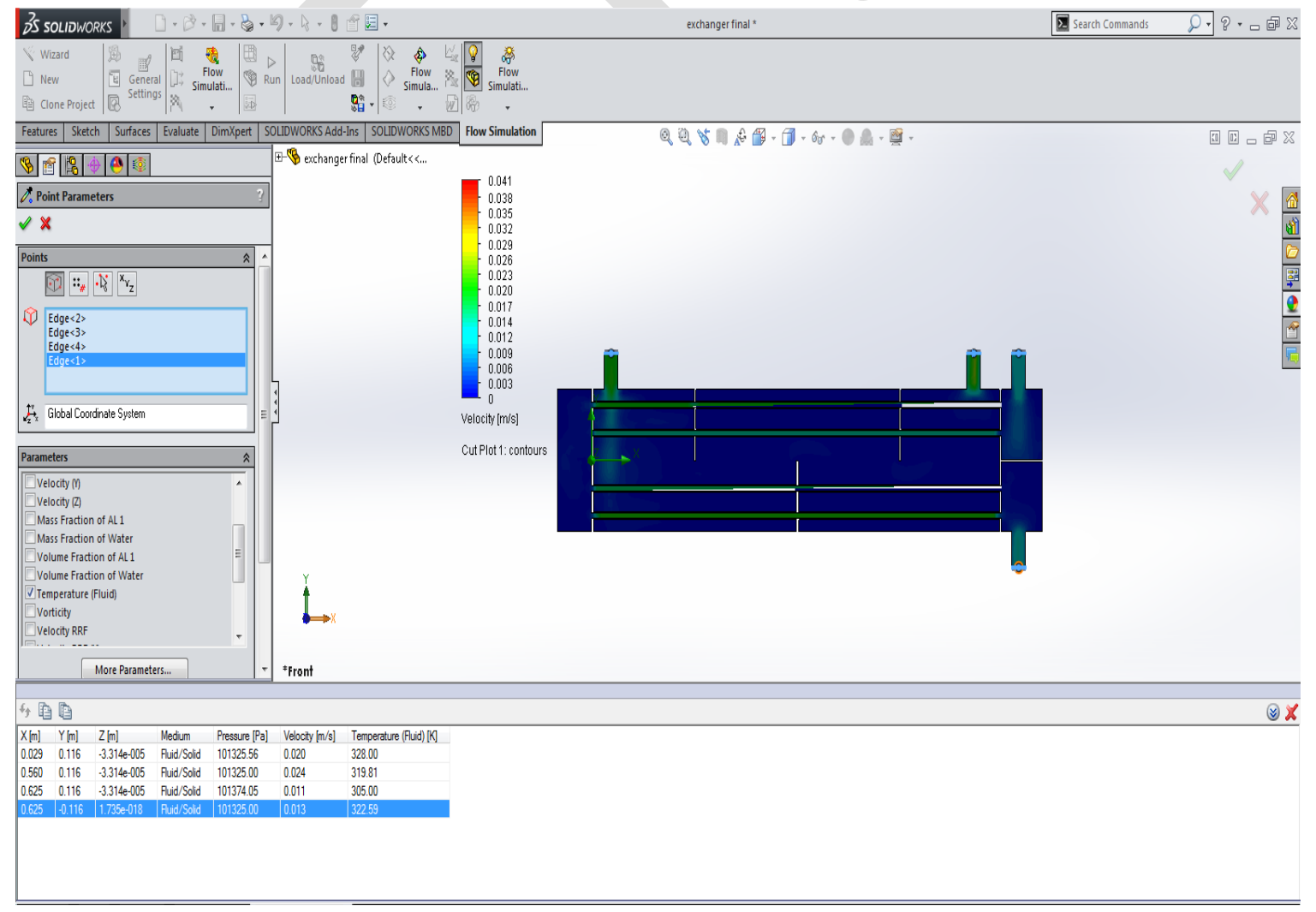

Fig: Temperature velocity and pressure readings in shell and tube 


\begin{tabular}{|c|c|r|}
\multicolumn{3}{|c|}{ Al2O3-1 } \\
\hline $\begin{array}{c}\text { Pressure } \\
{[\mathrm{Pa}]}\end{array}$ & $\begin{array}{c}\text { Velocity } \\
{[\mathrm{m} / \mathrm{s}]}\end{array}$ & $\begin{array}{c}\text { Temperature } \\
\text { (Fluid) }[\mathrm{K}]\end{array}$ \\
\hline 101325.5558 & 0.019949847 & 328 \\
\hline 101325.0015 & 0.023509442 & 319.8145848 \\
\hline 101374.0488 & 0.011092198 & 305 \\
\hline 101325.0044 & 0.01329332 & 322.5914792 \\
\hline
\end{tabular}

Table $\mathrm{si}_{2} 1 \%+99 \%$ water readings

\begin{tabular}{|r|l|r|}
\hline \multicolumn{3}{|c|}{ SiO2-1 } \\
\hline Pressure $[\mathrm{Pa}]$ & $\begin{array}{l}\text { Velocity } \\
{[\mathrm{m} / \mathrm{s}]}\end{array}$ & $\begin{array}{l}\text { Temperature } \\
\text { (Fluid) }[\mathrm{K}]\end{array}$ \\
\hline 101325.558 & 0.019949847 & 328 \\
\hline 101325.0025 & 0.02355719 & 317.937088 \\
\hline 101372.4453 & 0.011383896 & 305 \\
\hline 101325.0045 & 0.013645461 & 320.759435 \\
\hline
\end{tabular}

\begin{tabular}{|c|c|c|}
\hline \multicolumn{3}{|c|}{ Al2O3-2 } \\
\hline $\begin{array}{c}\text { Pressure } \\
{[\mathrm{Pa}]}\end{array}$ & $\begin{array}{c}\text { Velocity } \\
{[\mathrm{m} / \mathrm{s}]}\end{array}$ & $\begin{array}{c}\text { Temperature } \\
\text { (Fluid) }[\mathrm{K}]\end{array}$ \\
\hline 101325.5553 & 0.019949847 & 328 \\
\hline 101325.0047 & 0.013258371 & 323.0068923 \\
\hline 101376.3634 & 0.01104978 & 305 \\
\hline 101325.0021 & 0.023519898 & 320.4278744 \\
\hline
\end{tabular}

Table si02 2\%+98\% water readings

\begin{tabular}{|l|l|r|}
\hline \multicolumn{3}{|c|}{ SiO2-2 } \\
\hline $\begin{array}{l}\text { Pressure } \\
{[\mathrm{Pa}]}\end{array}$ & $\begin{array}{l}\text { Velocity } \\
{[\mathrm{m} / \mathrm{s}]}\end{array}$ & $\begin{array}{l}\text { Temperature } \\
\text { (Fluid) }[\mathrm{K}]\end{array}$ \\
\hline 101325.5571 & 0.019949847 & 328 \\
\hline 101325.0021 & 0.023398994 & 317.9352704 \\
\hline 101372.9936 & 0.011243259 & 305 \\
\hline 101325.0046 & 0.013477976 & 320.7845438 \\
\hline
\end{tabular}

\section{CONLUSION}

It is observed that the thermal conductivity of water is not much change with temperature. As we go for higher concentration ( 0.1 to $0.5 \%)$.the thermal conductivity increases but at temperature $54^{\circ} \mathrm{C}$ drop in conductivity is observed. It is found that the thermal conductivity increases significantly with the nanoparticle volume fraction. With an increase of temperature, the thermal conductivity increases for a certain volume concentration of Nano fluids, but the viscosity decreases. The temperature and volume fractions have significant effects on the thermal conductivity and viscosities are investigated. Addition of small amount of alumina nanoparticles transforms the Newtonian behavior of Nano fluid to a non- Newtonian fluid and it behaves as Bingham plastic with small yield stress. Viscosity of Nano fluid (Al2O3/water and sio2 and water) is less than base fluid water. Specific heat of Nano fluid decreases with the concentration as increases. (1 to $2 \%$ ). Density of Nano fluid 
(Al2O3/water and sio2 and water) decreases with temperatures but the density of Nano fluid is higher than base fluid's density. The density of Nano fluid increases with concentrations.

\section{REFERENCES}

[1] Kotcherla Sriharsha, Venkata Ramesh Mamillaand M.V. Mallikarjun" Strength Analysis of Tube to Tube Sheet Joint in Shell and Tube Heat Exchanger"

[2] Hardik.B.Patel, N.S.Mehta "Optimum Inlet Temperatures In Shell And Tube Condenser Using Exergy Method"

[3] Prashant Sharma, SPS Rajput, Mukesh Pandey" Energy destruction analysis of X-type shell and tube single segmental baffle steam condenser with various operating Conditions"

[4] Sandeep K. Patel, Professor Alkesh M. Mavani "Shell \& Tube Heat Exchanger Thermal Design With Optimization of Mass Flow Rate and Baffle Spacing"

[5] Jian-Fei Zhang, Ya-Ling He, Wen-Quan Tao" A Design and Rating Method for

Shell-and-Tube Heat Exchangers with Helical Baffles"

[6] S. Noie Baghban, M. Moghiman and E. Salehi "Thermal Analysis of Shell-Side Flow Of Shell-And Tube Heat Exchanger Using Experimental and Theoretical methods"

[7] A. Khiabani, N.M. Adam, T.S. Hong and M. Ali "Design of Portable Shell and Tube Heat Exchanger for a Solar Powered Water Distiller".

[8] M. Thirumarimurugan, T.Kannadasan and E.Ramasamy "Performance Analysis of Shell and Tube Heat Exchanger Using Miscible System"

[9] S. N. Hossain, S Bari "Effect of different working fluids on shell and tube heat exchanger to recover heat from exhaust of an automotive diesel engine".

[10] B. V. Babu* and S. A. Munawar "Optimal Design of Shell-and-Tube Heat Exchangers by Different Strategies of Differential Evolution".

[11] Prof. Paul Amitesh "Optimization in Area by Changing Number of Passage in Shell of Surface Condenser"

[12] Žarko Stevanović, Gradimir Ilić, Nenad Radojković,,Mića Vukić,Velimir Stefanović,Goran Vučković "Design Of Shell-And-Tube Heat Exchangers By

Using Cfd Technique"

[13] A.GopiChand, Prof.A.V.N.L.Sharma,G.Vijay Kumar, A.Srividya "Thermal Analysis Of Shell And Tube Heat Exchangerusing Mat Lab And Floefd Software"

[14] B. Jabbari, N. Tahouni and M. H. Panjeshahi "Optimum Design of an Absorption Heat Pump Integrated with a Kraft Industry using Genetic Algorithm"

[15] F. Vera-García, J.R. García-Cascales, J. Gonzálvez-Maciá, R. Cabello,, R. Llopis, D. Sanchez, E. Torrella," A simplified model for shell-and-tubes heat exchangers: Practical application"

[16] Heat transfer data tables 